\title{
不同受体单元的两个聚合物光伏性质
}

\author{
秦瑞平* 耿凡 王丹丰 姚小静 \\ (河南师范大学物理与电子工程学院 河南省光伏材料重点实验室 新乡 453007)
}

\begin{abstract}
摘要 合成了两个不同受体的共轭聚合物联噻唑-苯并噻二唑-咔唑共聚物(HSD-5); 四氟苯-并二噻吩-咔唑共聚物 (HSD-7), 研究了其热学、光物理和光伏性质. 由电化学结果显示两个聚合物的带隙分别为 2.16 和 $2.53 \mathrm{eV}$. 用聚合物/ [6,6]-苯基-C71-丁酸甲酯(PC71BM)作为活性层构筑了本体异质结聚合物太阳能电池的能量转换效率分别为 $0.36 \%$ 和 $0.73 \%$. 同时，研究表明含氟材料由于碳一氟键高度极化改变了聚合物分子间的作用力，对活性层的形貌产生显著影响; 多元受体单元间较大的扭转角会降低共轭电子离域程度, 不利于分子内因电荷转移对光子的吸收, 拓宽了聚合物的能 带隙. 最后, 结合实验结果分析了两种材料制备的器件能量转换效率较低的原因.
\end{abstract}

关键词 受体; 共轭聚合物; 异质结太阳能电池; 含氟受体

\section{Photovoltaic Property of Two Polymers Furnished by Different Acceptor Bolcks}

\author{
Qin, Ruiping* Geng, Fan Wang, Danfeng Yao, Xiaojing \\ (Key Laboratory of Photovoltaic Materials of Henan Province, College of Physics \& Electronic Engineering, \\ Henan Normal University, Xinxiang 453007)
}

\begin{abstract}
Two conjugated copolymers poly[4-(4,4'-dinonyl-2,2'-bithiazol-5-yl)-7-(4,4'-dinonyl-5'-(9-octyl-9H-carbazol2-yl)-2,2'-bithiazol-5-yl)benzo[c][1,2,5]thiadiazole] (HSD-5) and poly[9-octyl-2-(5-(2,3,5,6-tetrafluoro-4-(3-undecylthieno[3,2-b]thiophen-2-yl)phenyl)-6-undecylthieno[3,2-b]thiophen-2-yl)-9H-carbazole] (HSD-7) were synthesized and their photophysical and photovoltaic properties were studied. The electrochemical characterization results showed that these two polymer possessed wide band-gaps of 2.16 and $2.53 \mathrm{eV}$, respectively. Solar cell devices based on polymer/PC71BM gave a power conversion efficiency (PCE) of $0.36 \%$ and $0.73 \%$ for HSD-5 and HSD-7, respectively. For the fluorine containing polymer HSD-7, the strong electronegativity of fluorine induces a strong dipole moment along the $\mathrm{C}-\mathrm{F}$ bond, which resulted in a strong inter/intramolecular interaction and displayed significant influnce on the morphology of the active layer. Meanwhile, the large torsion angles between the acceptor blocks destroyed the conjugation and the electron delocalization. Finally, the structure-activity relationship was also discussed to understand the reason of the low power conversion efficiency (PCE).

Keywords acceptor; conjugated polymer; bulk-heterojunction solar cells; fluorinated blocks
\end{abstract}

近年来, 聚合物太阳能电池的能量转换效率突破了 $10 \%{ }^{[1]}$, 已经接近工业化生产的要求. 中国在光伏研究 领域异军突起, 成绩令人振奋 ${ }^{[2]}$. 关键的问题是深入理 解半导体聚合物化学结构和光伏性质间的关系 ${ }^{[3]}$, 成功 的办法是设计具有给一受体结构的共轭聚合物使之能较 好地匹配太阳发射光谱 ${ }^{[4]}$, 新的聚合物给体材料不仅需 要具有宽的光谱吸收范围, 高的吸收系数, 还需要给/受 体材料构成的活性层具有较高且平衡的载流子迁移
率 $^{[5]}$. 为了使共轭主链电子有较大的离域范围, 聚合物 分子应具有平面性, 以利于增加电子有效共轭长度 ${ }^{[6]}$. 不同的富电子的给体和缺电子的受体可以调整共聚物 的综合性质. 一般认为给体单元决定了聚合物分子的最 高电子占有轨道能级(HOMO 能级), 受体单元决定了聚 合物分子的最低电子未占轨道能级(LUMO 能级) $)^{[7]}$. 不 改变富电子给体单元, 采用多元的或不同的共轭单元作 为受体，研究聚合物结构和性质间的关系具有重要意

\footnotetext{
* E-mail: qinruiping@163.com
}

Received May 18, 2015; revised July 9, 2015; published online August 25, 2015.

Project supported by the Young Scientists Foundation of Henan Normal University (No. 01026400061), the Henan Province Basic and Frontier Technology Research Projects (No. 1323004100247) and the College Students' Innovative Pilot Scheme (No. 2012011).

河南师范大学青年基金(No. 01026400061)、河南省基础与前沿技术研究计划(No. 1323004100247)、大学生创新(No. 2012011)资助项目. 
义. 如果将联噻唑 ${ }^{[8]}$ 与苯并噻二唑偶联作为受体或者将 平面的并环噻吩 $[3,2-b]$ 并噻吩 ${ }^{[9]}$ 与四氟苯偶联作为受体, 调整聚合物骨架的能级, 同时兼顾边链的影响, 选择不 带分叉的烷基链. 利用多重受体单元或强拉电子的四氟 苯单元合成较低 HOMO 能级的聚合物具有一定的意义, 本文合成了这样结构的两个给-受体型共轭聚合物联噻 唑-苯并噻二唑一咔唑共聚物(HSD-5)、四氟苯-并二噻 吩一咔唑共聚物(HSD-7) (Scheme 1). 以聚合物为给体材 料、 $[6,6]$-苯基 $\mathrm{C}_{71}$ 丁酸甲酯 $\left(\mathrm{PC}_{71} \mathrm{BM}\right)$ 为受体材料制备了 本体异质结型太阳能电池, 该太阳能电池的能量转换效 率达到了 $0.73 \%$ (HSD-7) 和 $0.36 \%$ (HSD-5). 试验的电池 没有使用活性层添加剂或界面修饰层.

\section{1 结果与讨论}

\section{1 合成}

如 Scheme 1 所示，化合物 5 和 1,4-二溴-2,3,5,6-四 氟苯经零价钯催化的 Stille 交叉偶联反应不能得到产物 8, 可能由于 1,4 -二溴-2,3,5,6-四氟苯氟原子强烈的电负 性使零价钯不能插入溴-碳键之间. 但是改由 1,4-二溴2,3,5,6-四氟苯经 Miyaura borylation 制备硼酸酯, 然后 “一锅法” 和芳基溴化物 2-溴-3-十一烷基噻吩并 [3,2-b] 噻吩反应，高产率(70\%)地合成了化合物 8 . 含氟的材料 由于易形成氢键, 因此不能经硅胶柱色谱分离法得到纯 的嗍酸酯. 直接偶联的 “一锅法” 简单易行.

\section{2 光物理性质和热稳定性}

图 1 为聚合物的氯仿溶液和薄膜的紫外-可见光吸 收光谱. 在溶液中, HSD-5 的吸收峰在 $250 \sim 550 \mathrm{~nm}$ 之 间有多个吸收峰。在膜中, HSD-5 吸收峰红移到了 $250 \sim 600 \mathrm{~nm}$. HSD-7 的吸收峰在 $250 \sim 450 \mathrm{~nm}$ 之间也出 现多个吸收峰. 由于 HSD-7 在四氟苯单元和并二噻吩 间的二面角很大, 破坏了电子的共轭离域, 分子内电荷 转移吸收峰不如 HSD-5 与太阳发射峰匹配. 在膜中, HSD-7 吸收峰没有明显红移. 说明含氟的聚合物分子间 有较弱的聚集效应. HSD-5 的 5\%失重的热分解温度为 $298{ }^{\circ} \mathrm{C}$, HSD-7 分子量明显高于 HSD-5. 其热稳定性更 好, $5 \%$ 失重的热分解温度为 $402.4{ }^{\circ} \mathrm{C}$ (图 2).

\section{3 聚合物的能级和电池微观形貌}

由循环伏安曲线按照 $E_{\mathrm{HOMO}}=-\left(E_{\mathrm{ox}}-F \mathrm{c}_{\mathrm{ox}}+4.8\right)$ $\mathrm{eV}, E_{\text {band gap }}=1240 / \lambda_{\text {onset }}$ 和 $E_{\mathrm{LUMO}}=E_{\mathrm{HOMO}}-E_{\text {band gap }}$ 计算 聚合物的 HOMO 能级: HSD-5 为 $-5.65 \mathrm{eV}, \mathrm{HSD}-7$ 为 $-5.38 \mathrm{eV}$. LUMO 能级为: HSD-5 为 $-3.49 \mathrm{eV}, \mathrm{HSD}-7$ 为 $-2.85 \mathrm{eV}$. 能带隙 HSD-5 为 $2.16 \mathrm{eV}, \mathrm{HSD}-7$ 为 2.53 $\mathrm{eV}$. 两个聚合物能带隙较宽, 主要是由于多元受体单元 间较大的扭转角破坏了体系的共轭程度, 不利于分子内
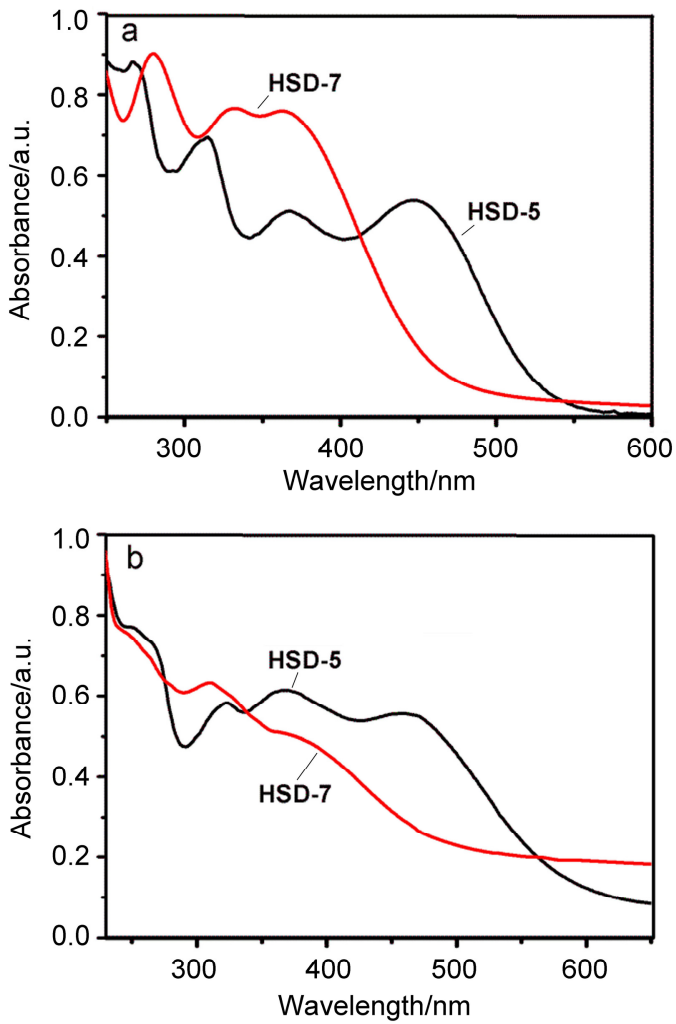

图 1 聚合物氯仿溶液中(a)和膜中的吸收光谱(b)

Figure 1 UV-Vis spectra of polymer (a) in chloroform and (b) films

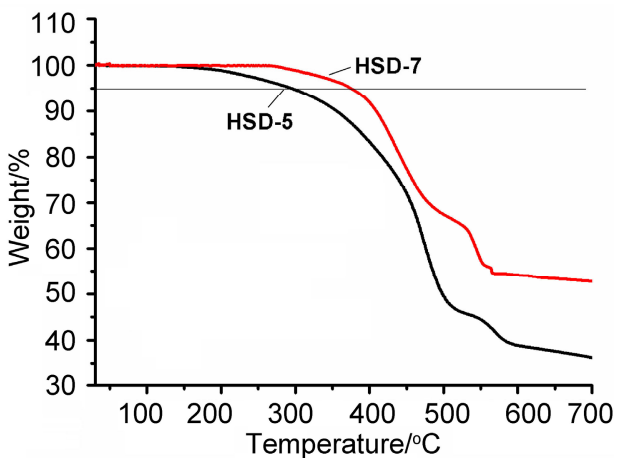

图 2 聚合物 HSD-5 和 HSD-7 热分解性能

Figure 2 TGA curves of HSD-5 and HSD-7

给-受体间电荷有效转移. HSD-5, HSD-7 和受体 $\mathrm{PC}_{71} \mathrm{BM}$ 的 LUMO 能级差分别为 0.81 和 $1.45 \mathrm{eV}$. 因此 基于 HSD-7 和受体 $\mathrm{PC}_{71} \mathrm{BM}$ 构筑的电池异质结界面电荷 分离效率较高, 电池短路电流密度(HSD-7: $5.58 \mathrm{~mA}$ $\mathrm{cm}^{-2}$ )较大(HSD-5: $1.32 \mathrm{~mA} \cdot \mathrm{cm}^{-2}$ ). 互穿网络结构的活 性层微相分离形貌对电池性能有至关重要的影响. 从图 3 扫描电镜图像可以看出, HSD-5 活性层表面有裂缝, 会降低载流子传输距离和电荷在电极收集效率, 这是短 路电流密度较低的一个主要因素. 两个聚合物吸收光谱 与太阳最大发射光谱不匹配也是效率低的重要原因. 

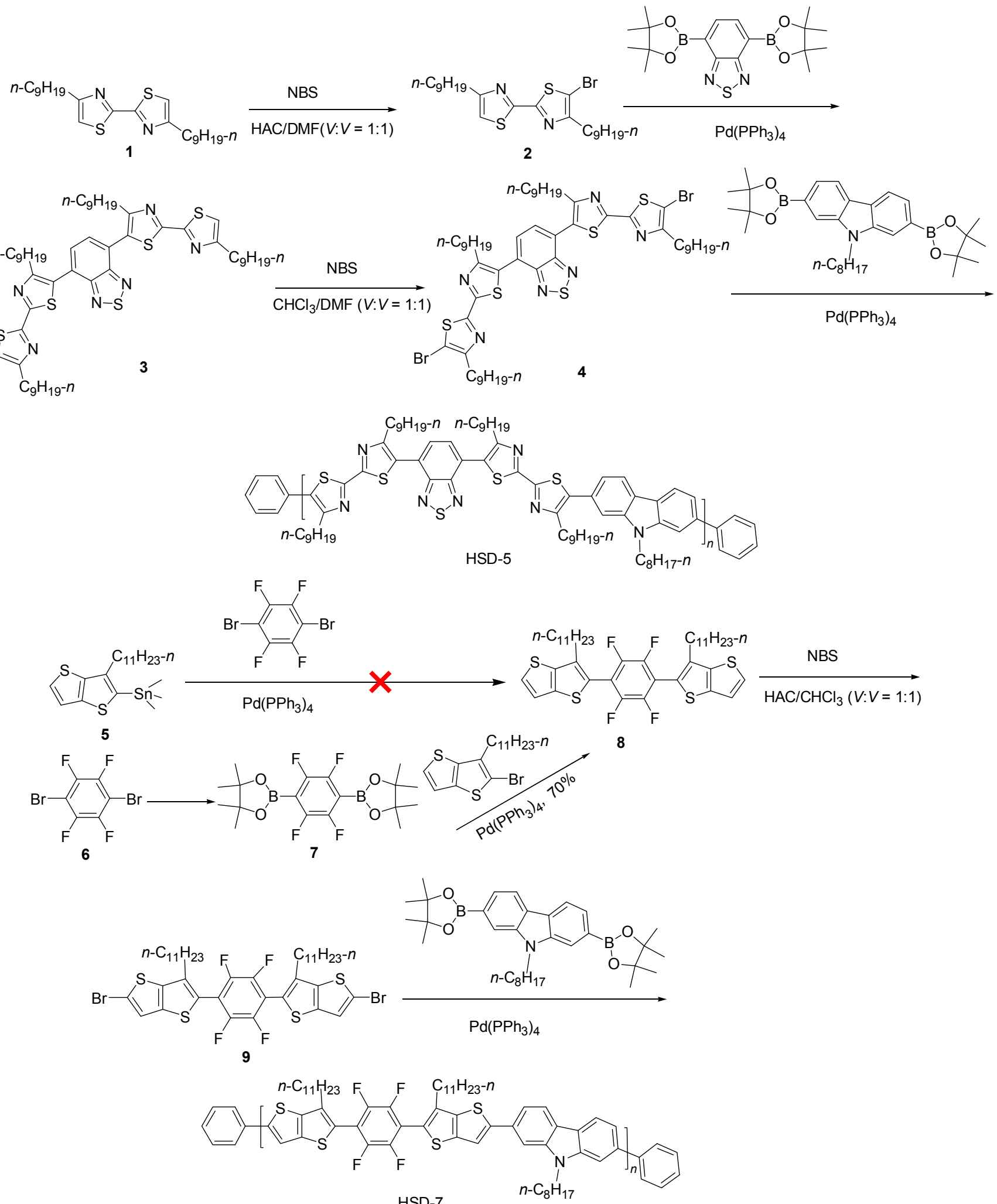

图式 1 聚合物 HSD-5 和 HSD-7 合成路线

Scheme 1 Synthetic route of polymer HSD-5 and HSD-7

HSD-7 由于含氟材料的较低的表面能和较高的分 低的填充因子. HSD-5 RMS $=12.82 \mathrm{~nm}$; HSD-7 RMS $=$ 子量使活性层表面十分光滑, 较小的相畴尺寸导致了较 $0.88 \mathrm{~nm}$. 但是较小的异质结中激子可以有效扩散到两 


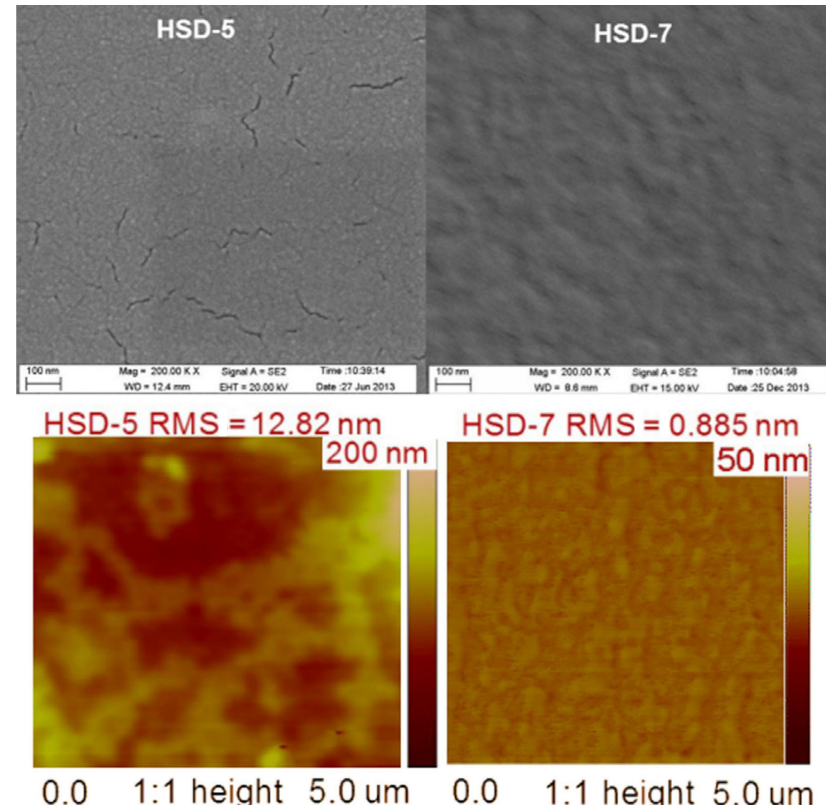

图 3 活性层电子扫描(上)和原子力扫描显微图(下) $(5.0 \mu \mathrm{m} \times$ $5.0 \mu \mathrm{m})$

Figure 3 SEM (top) and AFM height (bottom) of the surface of active layer $(5.0 \mu \mathrm{m} \times 5.0 \mu \mathrm{m})$

相界面，容易实现高的短路电流.

\section{4 电池的光伏特性}

电池的电流密度和电压 $I$ 与 $V$ 关系曲线如图 4 所示. 基于 $\mathrm{HSD}-5 / \mathrm{PC}_{71} \mathrm{BM}$ 的电池能量转换效率为 $0.37 \%$, 器 件的开路电压 $V_{\mathrm{oc}}$ 为 $0.82 \mathrm{~V}$, 短路电流为 $1.53 \mathrm{~mA} / \mathrm{cm}^{2}$, 填充因子 $\mathrm{FF}$ 值为 0.33 . 基于 $\mathrm{HSD}-7 / \mathrm{PC}_{71} \mathrm{BM}$ 的电池能 量转换效率为 $0.73 \%$, 器件的开路电压 $V_{\mathrm{oc}}$ 为 $0.62 \mathrm{~V}$, 短 路电流为 $5.58 \mathrm{~mA} / \mathrm{cm}^{2}$, 填充因子 $\mathrm{FF}$ 值为 0.27 . 电池光 电转换效率较低的原因主要是活性层形貌不理想、相畴 尺寸太小、能带隙太大、吸光系数低、吸收光谱与太阳 发射光谱匹配不好. 另外从图 4 器件的暗电流特性曲线 可以看出, 基于 HSD-5 的器件有微弱的电流泄漏.

\section{2 结论}

本文报道了两个不同受体单元共轭聚合物 HSD-5 和 HSD-7, 研究了其热学、光物理和光电转换性质. 这 种多元受体交替结构的共轭聚合物共轭效应较小, 具有 较大的能隙. 以这两种聚合物为给体材料、 PC71BM 为 受体材料制备了本体异质结聚合物太阳能电池. 其中含 氟的 HSD-7 获得了大的短路电流 $5.58 \mathrm{~mA} / \mathrm{cm}^{2}$, 适当的 开路电压 $0.62 \mathrm{~V}$, 较低的填充因子 $\mathrm{FF}$ 值 0.33 . 光伏电池 的能量转换效率达到了 $0.73 \%$. 含氟材料由于碳一氟键 高度极化极大地改变了聚合物分子间的作用力, 影响活 性层的形貌. 多元受体单元间较大的扭转角会降低共轭 电子离域程度, 使吸收光谱蓝移, 扩大聚合物的能带隙. 不利于拓宽分子内电荷转移吸收光谱.

\section{3 实验部分}

\section{1 仪器与试剂}

3,4-乙撑二氧噻吩聚合物-聚苯乙烯磺酸盐(PEDOT. PSS)溶液(Baytron-PVP AI 4083)(德国 Bayer 公司, 1\% $2 \%$ 固含量); PC71BM 加拿大(American Dye Source 公 司); 其它试剂均购自 Aldrich. 所有反应均在 $\mathrm{N}_{2}$ 气氛围 下进行. Bruker(DMX400)型核磁共振仪 $\left({ }^{1} \mathrm{H}\right.$ NMR, ${ }^{13} \mathrm{C}$ $\mathrm{NMR}$ ); 基质辅助激光解析电离飞行时间质谱(MALDITOF-MS)测试在 Bruker 质谱仪上进行; UV-3600 Shimadzu 紫外-可见光谱仪; NETZSCH STA 449F3 热分析 仪, $\mathrm{N}_{2}$ 气流速 $20 \mathrm{~mL} / \mathrm{min}$, 升温速率为 $10{ }^{\circ} \mathrm{C} / \mathrm{min}$; 循环 伏安(CV)(电化学工作站 IviumStat A25361)采用三电极 模式, 玻碳电极为工作电极, 铂丝为对电极, 银/氯化银 参比电极, 六氟磷酸四丁基铵的乙氭溶液 $(0.1 \mathrm{~mol} / \mathrm{L})$ 作 为支持电解质, 实验由 ferrocene/ferrocenium $\left(\mathrm{Fc}^{+} / \mathrm{Fc}\right)$ 氧 化还原体系校准，扫描速率 $100 \mathrm{mV} \cdot \mathrm{s}^{-1}$, 假定二茂铁的 真空能级为 $4.8 \mathrm{eV}$; Waters 2695 型凝胶渗透色谱仪 $(\mathrm{GPC})$, 以四氢呋喃 THF 为流动相、窄分布聚苯乙烯为
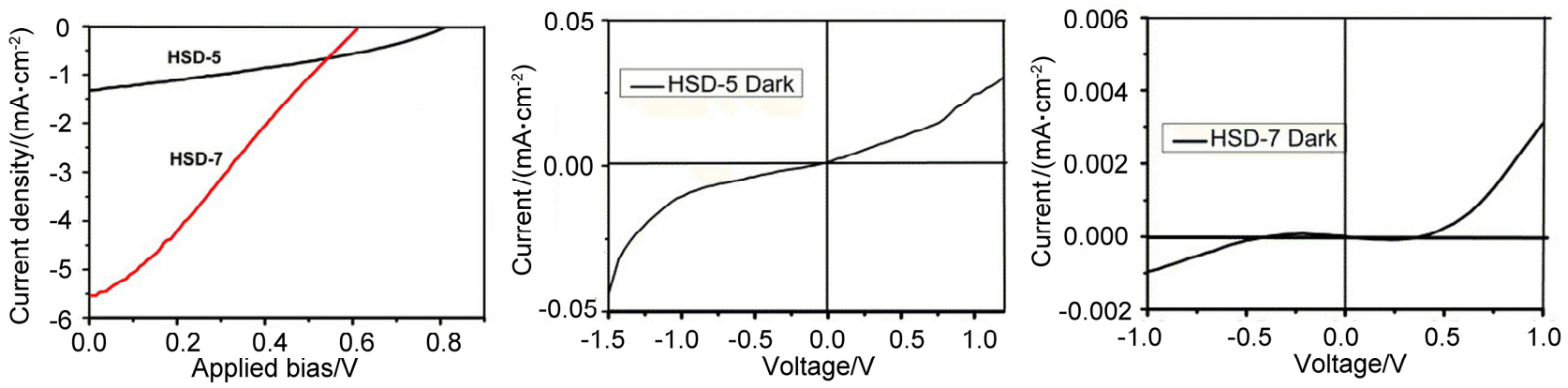

图 4 电池 ITO/PEDOT:PSS/polymer:PC71BM $[m($ polymer) $: m(\mathrm{PC} 71 \mathrm{BM})=1: 3] / \mathrm{Al}$ 电流-电压曲线(左)和暗电流特性曲线(中和 右)

Figure $4 J-V$ curves of photovoltaic cells with a device structure of ITO/PEDOT:PSS/polymer:PC ${ }_{71} \mathrm{BM}\left[m(\right.$ polymer $): m\left(\mathrm{PC}_{71} \mathrm{BM}\right)=$ $1: 3] / \mathrm{Al}$ (left), and the dark $J-V$ curves of the same device (middle and right) 
标样, 测试温度 $35{ }^{\circ} \mathrm{C}$; 扫描探针显微镜 (Veko SPM); SUPRA40 电子扫描显微镜; 太阳光模拟器(Newport3A) 作为光源, Keithley236 电流-电压表测试电池效率.

\section{2 聚合物的合成}

化合物 $\mathbf{1}^{[7 b]}$ 和 $5^{[8 b]}$ 参照文献方法合成.

\subsubsection{5-溴-4,4'-二壬基-2,2'-双噻唑(2)的合成}

在 $500 \mathrm{~mL}$ 圆底烧瓶中加入 $N, N$-二甲基甲酰胺 (DMF) $50 \mathrm{~mL}$, 醋酸 $50 \mathrm{~mL}, 5.8 \mathrm{~g}$ (13.78 mmol) 4,4'-二壬 基-2,2'-二噻唑 (1), 加入 $N$-溴代丁二酰亚胺(NBS) 2.44 g (13.7 $8 \mathrm{mmol})$, 避光室温反应 $6 \mathrm{~h}$, 用二氯甲烷 150 $\mathrm{mL}$, 水 $300 \mathrm{~mL}$, 分三次萃取, 经无水硫酸钠干燥后减 压蒸掉有机溶剂, 混合物经硅胶色谱柱分离 $[V($ 石油 醚) $: V($ 二氯甲烷 $)=10: 1$ 为洗脱液]. 得淡黄色透明油 状液体 $5.4 \mathrm{~g}$, 产率 $91 \%$. 长时间放置后为针状黄色晶 体, m.p. $48.5 \sim 50.6{ }^{\circ} \mathrm{C}$; UV-vis (THF) $\lambda_{\max }: 341.55 \mathrm{~nm} ;{ }^{1} \mathrm{H}$ NMR (400 MHz, $\left.\mathrm{CDCl}_{3}\right) \delta: 6.94(\mathrm{~s}, 1 \mathrm{H}), 2.81 \sim 2.73(\mathrm{~m}$, $4 \mathrm{H}), 1.73 \sim 1.67(\mathrm{~m}, 4 \mathrm{H}), 1.35 \sim 1.26(\mathrm{~m}, 24 \mathrm{H}), 0.88$ (br, $6 \mathrm{H}) ;{ }^{13} \mathrm{C}$ NMR $\left(400 \mathrm{MHz}, \mathrm{CDCl}_{3}\right) \delta: 160.66,160.17$, 159.34, 157.19, 114.81, 106.28, 54.46, 31.91, 31.18, 29.54, $29.32,29.17,28.74,22.69,14.10$.

3.2.2 4,7-双 (4,4'-二壬基-2,2'-双噻唑-5-基) 苯并 $[c][1,2,5]$ 噻二唑 $(3)$ 的合成

在 $250 \mathrm{~mL}$ 带截门圆底烧瓶中, 加入 $2.0 \mathrm{~g}$ 化合物 2 (4 mmol), 2,1,3-苯并噻二唑-4,7-二(频哪醇)二硼酸脂 $0.78 \mathrm{~g}(1.9 \mathrm{mmol}), \mathrm{THF}(30 \mathrm{~mL})$, 水 $(6 \mathrm{~mL})$, 碳酸钠 $(1.2$ g), $50 \mathrm{~mL}$ 甲苯和 $50 \mathrm{mg} \mathrm{Pd}\left(\mathrm{PPh}_{3}\right)_{4}$. 混合物在 $70{ }^{\circ} \mathrm{C} 、 \mathrm{~N}_{2}$ 气保护下反应 $48 \mathrm{~h}$. 用 $150 \mathrm{~mL}$ 二氯甲烷和 $300 \mathrm{~mL}$ 水分 三次萃取, 经无水硫酸钠干燥后减压蒸掉有机溶剂, 混 合物经硅胶色谱柱分离 [石油醚/二氯甲烷 $(V: V=10$ : 1)作为洗脱液]得金黄色固体 $3.6 \mathrm{~g}$, 产率 $92 \%$. m.p. 73.7 75.3 ${ }^{\circ} \mathrm{C}$; UV-vis (THF) $\lambda_{\max }: 347.6,423.55 \mathrm{~nm} ;{ }^{1} \mathrm{H}$ NMR (400 MHz, $\left.\mathrm{CDCl}_{3}\right) \delta: 7.77(\mathrm{~s}, 2 \mathrm{H}), 7.01(\mathrm{~s}, 2 \mathrm{H})$, $2.92 \sim 2.82(\mathrm{~m}, 8 \mathrm{H}), 1.84 \sim 1.74(\mathrm{~m}, 8 \mathrm{H}), 1.35 \sim 1.21(\mathrm{~m}$, $48 \mathrm{H}), 0.87 \sim 0.83(\mathrm{~m}, 12 \mathrm{H}) ;{ }^{13} \mathrm{C} \mathrm{NMR}\left(400 \mathrm{MHz}, \mathrm{CDCl}_{3}\right.$ ) $\delta: 160.95,160.70,159.43,156.80,153.76,129.47,128.29$, $125.41,115.01,31.90,31.56,30.60,29.56,29.45,29.41$, 29.28, 22.69, 14.11; MALDI-TOF $m / z$ : 973.7.

3.2.3 4,7-双(5'-溴-4,4'-二壬基-2,2'-双噻唑-5-基)苯并 [c][1,2,5]塞二唑(4)的合成

在 $250 \mathrm{~mL}$ 圆底烧瓶中加入 $\mathrm{DMF} 50 \mathrm{~mL}$, 氯仿 50 $\mathrm{mL}, 1.5 \mathrm{~g}$ 化合物 3 (1.5 mmol), $N$-溴代丁二酰亚胺(NBS) $1 \mathrm{~g}(4.6 \mathrm{mmol})$, 避光室温反应 $12 \mathrm{~h}$, 用 $150 \mathrm{~mL}$ 二氯甲烷 和 $300 \mathrm{~mL}$ 水分三次萃取, 有机相无水硫酸钠干燥后减 压蒸掉溶剂, 经硅胶色谱柱纯化 $[V$ (石油醚) : $V$ (二氯甲
烷) $=10: 1$ 为洗脱液]得紫红色固体 $1.9 \mathrm{~g}$, 产率 $\approx 100 \%$. m.p. $98.5 \sim 100.4{ }^{\circ} \mathrm{C}$; UV-vis (THF) $\lambda_{\max }: 358.82,425.28$ $\mathrm{nm} ;{ }^{1} \mathrm{H}$ NMR $\left(400 \mathrm{MHz}, \mathrm{CDCl}_{3}\right) \delta: 7.76(\mathrm{~s}, 2 \mathrm{H}), 2.90 \sim$ $2.76(\mathrm{~m}, 8 \mathrm{H}), 1.84 \sim 1.73(\mathrm{~m}, 8 \mathrm{H}), 1.66 \sim 1.22(\mathrm{~m}, 48 \mathrm{H})$, 0.87 (br, $12 \mathrm{H}) ;{ }^{13} \mathrm{C}$ NMR $\left(400 \mathrm{MHz}, \mathrm{CDCl}_{3}\right) \delta: 160.45$, $160.34,157.55,156.94,153.69,129.47,128.50,125.35$, $106.85,31.88,30.53,29.60,29.51,29.39,29.31,29.28$, 29.18, 28.76, 22.66, 14.00; MALDI-TOF $m / z$ : 1131.6.

$3.2 .42,2^{\prime}$-(全氟-1,4-苯基)双(3-十一烷基噻吩并 [3,2$b]$ 噻吩) (8)的合成

方法一: 在 $250 \mathrm{~mL}$ 带截门圆底烧瓶中, 加入 $5.94 \mathrm{~g}$ 化合物 5 (13 mmol), 1,4-二溴-2,3,5,6-四氟苯 $3.0 \mathrm{~g} \mathrm{(5.9}$ $\mathrm{mmol}), 100 \mathrm{~mL}$ 甲苯和 $100 \mathrm{mg} \mathrm{Pd}\left(\mathrm{PPh}_{3}\right)_{4}$. 混合物在 $\mathrm{N}_{2}$ 气保护下回流反应 $24 \mathrm{~h}$. 没有产物.

方法二：1,4-二澳-2,3,5,6-四氟苯(6)，1.0 g (3.2 $\mathrm{mmol})$, 醋酸钾 $(0.7 \mathrm{~g}, 0.68 \mathrm{mmol})$, 连硼酸频呐醇酯(1.81 g, $7.1 \mathrm{mmol})$, DMF $20 \mathrm{~mL}, \mathrm{Pd}(\mathrm{dppf})_{2} \mathrm{Cl}_{2} 100 \mathrm{mg}, \mathrm{N}_{2}$ 下 $80{ }^{\circ} \mathrm{C}$ 反应 $3 \mathrm{~d}$, 降至室温, 加入 $3.0 \mathrm{~g}(8.0 \mathrm{mmol}) 2$-溴-3十一烷基噻吩并 $[3,2-b]$ 噻吩, $10 \mathrm{~mL}$ 水, 碳酸钠 $(1.2 \mathrm{~g})$, $100 \mathrm{~mL}$ 甲苯和 $100 \mathrm{mg} \mathrm{Pd}\left(\mathrm{PPh}_{3}\right)_{4}$. 在 $\mathrm{N}_{2}$ 气下回流反应 48 $\mathrm{h}$, 用 $150 \mathrm{~mL}$ 二氯甲烷和 $300 \mathrm{~mL}$ 水分三次萃取, 无水硫 酸钠干燥后, 真空旋蒸蒸干, 混合物经硅胶色谱柱分离 $[V$ (石油醚) $: V($ 二氯甲烷 $)=10: 1$ 为洗脱液 $]$ 得黄色液体 $1.67 \mathrm{~g}$. 产率 $70 \%$. UV-vis (THF) $\lambda_{\text {max }}: 275.09,347.42 \mathrm{~nm}$; ${ }^{1} \mathrm{H}$ NMR $\left(400 \mathrm{MHz}, \mathrm{CDCl}_{3}\right) \delta: 7.39(\mathrm{~d}, J=5.27 \mathrm{~Hz}, 2 \mathrm{H})$, $7.17(\mathrm{~d}, J=5.20 \mathrm{~Hz}, 2 \mathrm{H}), 2.74(\mathrm{t}, J=2.70 \mathrm{~Hz}, 4 \mathrm{H}), 1.76 \sim$ $1.69(\mathrm{~m}, 4 \mathrm{H}), 1.34 \sim 1.27(\mathrm{~m}, 32 \mathrm{H}), 0.90(\mathrm{t}, J=6.62 \mathrm{~Hz}$, $6 \mathrm{H}) ;{ }^{13} \mathrm{C}$ NMR (400 MHz, $\left.\mathrm{CDCl}_{3}\right) \delta: 138.37,136.84$, $134.13,125.79,119.46,110.15,31.96,29.68,29.66,29.61$, 29.57, 29.40, 29.32, 29.21, 28.05, 22.74, 14.17 .

$3.2 .55,5^{\prime}$-(全氟-1,4-苯基)双(2-溴-6-十一烷基噻吩并 [3,2- $b]$ 噻吩) (9)的合成

在 $250 \mathrm{~mL}$ 圆底烧瓶中加入 $\mathrm{DMF}, 10 \mathrm{~mL}$, 氯仿 30 $\mathrm{mL}, 1.6 \mathrm{~g}$ 化合物 8 (2.3 mmol), NBS, $0.85 \mathrm{~g}$ (4.7 mmol), 避光室温反应 $24 \mathrm{~h}$, 减压蒸掉有机溶剂, 混合物经硅胶 色谱柱分离[石油醚作为洗脱液]得黄绿色油状液体 1.8 g. 产率 92.6\%. UV-vis (THF) $\lambda_{\max }: 283.72 \mathrm{~nm} ;{ }^{1} \mathrm{H}$ NMR $\left(400 \mathrm{MHz}, \mathrm{CDCl}_{3}\right) \delta: 7.15(\mathrm{~s}, 2 \mathrm{H}), 2.68(\mathrm{t}, J=7.50 \mathrm{~Hz}$, $4 \mathrm{H}), 1.68 \sim 1.65(\mathrm{~m}, 4 \mathrm{H}), 1.32 \sim 1.27(\mathrm{~m}, 32 \mathrm{H}), 0.90(\mathrm{t}$, $J=6.65 \mathrm{~Hz}, 6 \mathrm{H}) ;{ }^{13} \mathrm{C} \mathrm{NMR}\left(400 \mathrm{MHz}, \mathrm{CDCl}_{3}\right) \delta: 138.55$, $135.87,133.99,122.20,112.86,110.28,31.97,29.68$, $29.55,29.39,29.27,29.09,28.01,22.76,14.20$; MALDITOF $m / z: 892.7$.

3.2.6 聚合物 HSD-5 和 HSD-7 的合成

在 $100 \mathrm{~mL}$ 圆底烧瓶中, 加入咔唑嗍酸酯 ${ }^{[10]}(89 \mathrm{mg}$, 
$0.17 \mathrm{mmol})$ 、化合物 $4(0.19 \mathrm{~g}, 0.17 \mathrm{mmol})$ 、甲苯 $(10 \mathrm{~mL})$ 、 THF $(30 \mathrm{~mL})$ 、水 $(6 \mathrm{~mL})$ 、碳酸氢钠 $(1.2 \mathrm{~g}) 、 \mathrm{Pd}\left(\mathrm{PPh}_{3}\right)_{4}(5$ $\mathrm{mg})$. Suzuki 缩聚反应在氮气保护下、于 $70{ }^{\circ} \mathrm{C}$ 反应 $48 \mathrm{~h}$. 将得到的聚合物溶于 $200 \mathrm{~mL}$ 热的氯仿中, 过滤. 将滤 液浓缩至体积约 $50 \mathrm{~mL}$ 时, 倒入 $100 \mathrm{~mL}$ 丙酮中，过滤沉 淀物, 真空干燥, 得 $132 \mathrm{mg}$ 黑色粉末状产物, 收率 61\%. ${ }^{1} \mathrm{H}$ NMR $\left(400 \mathrm{MHz}, \mathrm{CDCl}_{3}\right) \delta: 8.17 \sim 7.97(\mathrm{~m}, 2 \mathrm{H}), 7.85 \sim$ $7.68(\mathrm{~m}, 3 \mathrm{H}), 7.54 \sim 7.46(\mathrm{~m}, 3 \mathrm{H}), 4.14(\mathrm{br}, 2 \mathrm{H}), 2.92 \sim$ $2.83(\mathrm{~m}, 8 \mathrm{H}), 1.85 \sim 1.76(\mathrm{~m}, 10 \mathrm{H}), 1.34 \sim 1.22(\mathrm{~m}, 74 \mathrm{H})$, 0.85 (br, $15 \mathrm{H}) ;{ }^{13} \mathrm{C}$ NMR $\left(400 \mathrm{MHz}, \mathrm{CDCl}_{3}\right) \delta: 161.03$, $160.74,159.47,156.82,153.78,132.64,132.17,132.12$, $132.07,131.61,129.47,128.66,128.54,115.05,31.92$, $29.63,29.56,29.48,29.35,29.31,29.26,22.72,22.70$, 14.15. 数均分子量 $3.67 \mathrm{~kg} / \mathrm{mol}$, 重均分子量 5.07 $\mathrm{kg} / \mathrm{mol}$ ，单分散指数 1.38 .

HSD-7 的合成同 HSD-5: 咔唑嗍酸酯(385 mg, 0.73 $\mathrm{mmol}) 、$ 化合物 $9(586 \mathrm{mg}, 0.73 \mathrm{mmol})$ 、甲苯 $(33 \mathrm{~mL})$ 、 THF $(80 \mathrm{~mL})$ 、水 $(20 \mathrm{~mL})$ 、碳酸氢钠 $(4 \mathrm{~g}) 、 \mathrm{Pd}\left(\mathrm{PPh}_{3}\right)_{4}(20$ $\mathrm{mg}$ ), 得 $166 \mathrm{mg}$ 黑色粉末状产物, 收率 35\%. ${ }^{1} \mathrm{H}$ NMR $\left(400 \mathrm{MHz}, \mathrm{CDCl}_{3}\right) \delta: 8.17 \sim 7.97(\mathrm{~m}, 2 \mathrm{H}), 7.85 \sim 7.68(\mathrm{~m}$, $3 \mathrm{H}), 7.54 \sim 7.46(\mathrm{~m}, 3 \mathrm{H}), 4.14(\mathrm{br}, 2 \mathrm{H}), 2.92 \sim 2.83(\mathrm{~m}$, $8 \mathrm{H}), 1.85 \sim 1.76(\mathrm{~m}, 10 \mathrm{H}), 1.34 \sim 1.22(\mathrm{~m}, 74 \mathrm{H}), 0.85(\mathrm{br}$, $15 \mathrm{H}) ;{ }^{13} \mathrm{C}$ NMR $\left(400 \mathrm{MHz}, \mathrm{CDCl}_{3}\right) \delta: 19.72,31.95,29.93$, $29.67,29.61,29.39,28.79,28.76,28.66,22.72,14.15$. 数 均分子量 $16.96 \mathrm{~kg} / \mathrm{mol}$, 重均分子量 $25.95 \mathrm{~kg} / \mathrm{mol}$, 单分 散指数 1.53 .

\section{3 太阳能电池的制备及电池性能的测试}

将聚合物 HSD-5 和 HSD-7 与 $\mathrm{PC}_{71} \mathrm{BM}$ 按质量比 1 : 3、按聚合物 $7 \mathrm{mg} / \mathrm{mL}$ 的质量浓度配成邻二氯苯溶液, 并 在手套箱中 $50{ }^{\circ} \mathrm{C}$ 搅拌 $12 \mathrm{~h}$. 用旋涂仪 (1600 r/min, $60 \mathrm{~s}$ ) 旋涂在预先涂有 $40 \mathrm{~nm}$ 的 PEDOT:PSS 薄膜的 ITO 导电 玻璃上, 厚度约为 $100 \mathrm{~nm}$. 真空热蒸镀 $100 \mathrm{~nm}$ 厚的 $\mathrm{A} 1$ 作为太阳能电池的负极, 电池的有效面积为 $0.04 \mathrm{~cm}^{2}$. 采用太阳光模拟器 (Oriel model 96,000)作为光源, 在光 强为 AM1.5 $\left(100 \mathrm{~mW} / \mathrm{cm}^{2}\right)$ 的条件下, 用 Keithley236 电 流一电压测试仪测定聚合物太阳能电池能量转换效率. 光强由标准硅太阳能电池在测量前校正.
辅助材料(Supporting Information) 聚合物电化学性 质及材料表征数据. 这些材料可以免费从本刊网站 (http://sioc-journal.cn/)上下载.

\section{References}

[1] (a) Liu, Y.; Zhao, J.; Li, Z.; Mu, C.; Ma, W.; Hu, H.; Jiang, K.; Lin, H.; Ade, H.; Yan, H. Nat. Commun. 2014, 5, 5293/1.

(b) Chen, J.-D.; Cui, C.; Li, Y.-Q.; Zhou, L.; Ou, Q.-D.; Li, C.; Li, Y.; Tang, J.-X. Adv. Mater. 2015, 27, 1035.

[2] Meng, Q.-B. Acta Chim. Sinica 2015, 73, 161 (in Chinese). (孟庆波, 化学学报, 2015, 73, 161.)

[3] (a) Qin, R.-P.; Li, W.-W.; Li, C.-H.; Du, C.; Veit, C.; Schleiermacher, H F.; Andersson, M.; Bo Z.-S.; Liu Z.-P.; Inganas, O.; Wuerfel, U.; Zhang, F.-L. J. Am. Chem. Soc. 2009, 131, 14612.

(b) Lei, T.; Wang, J.-Y.; Pei, J. Acc. Chem. Res. 2014, 47, 1117.

(c) Coughlin, J. E.; Henson, Z. B.; Welch, G. C. Acc. Chem. Res. 2014, 47, 257.

(d) Qin, R.-P.; Jiang, Y.-R.; Ma, H; Yang, L; Liu, H.-Z.; Chang, F.-G. J. Appl. Polym. Sci. 2013, 129, 2671.

(e) Qin, R.-P.; Song, G.-L.; Jiang, Y.-R.; Bo, Z.-S. Chem. J. Chin. Univ. 2012, 33, 828 (in Chinese).

(秦瑞平, 宋桂林, 蒋玉荣, 薄志山, 高等学校化学学报, 2012, 33, 828.)

(f) Liu, Z.; Xu, F.; Yan, D.-D. Acta Chim. Sinica 2014, 72, 171 (in Chinese).

(刘震, 徐丰, 严大东, 化学学报, 2014, 72, 171.)

[4] (a) Gong, X.; Li, C.; Lu, Z.; Li, G.; Mei, Q.; Fang, T.; Bo, Z.-S. Macromol. Rapid Commun. 2013, 34, 1163.

(b) Chen, Y.; Wan, X.; Long, G. Acc. Chem. Res. 2013, 46, 2645.

(c) You, J.; Dou, L.; Yoshimura, K. Nat. Commun. 2012, 4, 1446.

(d) Fan, X.-C.; Wang, F.; Li, X.-C.; Chen, Y.; Lai, W.-Y.; Huang, W. Chin. J. Org. Chem. 2014, 34, 2027 (in Chinese).

(范晓春, 王芳, 李祥春, 陈圭, 赖文勇, 黄维, 有机化学, 2014, 34, 2027.)

[5] (a) Wang, X.; Sun, Y.; Chen, S. Macromolecules 2012, 45, 1208. (b) Uy, R. L.; Price, S. C.; You, W. Macromol. Rapid Commun. 2012, 33, 1162.

(c) Li, Y.-F. Acc. Chem. Res. 2012, 45, 723.

(d) Du, C.; Li, W.; Li, C. J. Polym. Sci., Part A: Polym. Chem. 2012, 51, 383.

[6] (a) Lei, T.; Wang, J.-Y.; Pei, J. Chem. Mater. 2014, 26,594. (b) Hu, X.-L.; Zuo, L.-J.; Nan, Y.-X. Synth. Met. 2012, 162, 2005.

[7] (a) Brocks, G.; Tol, A. J. Phys. Chem. 1996, 100, 1838.

(b) Ajayaghosh, A. Chem. Soc. Rev. 2003, 32, 181.

[8] (a) Shi, Q.; Fan, H.; Liu, Y. Macromolecules 2011, 44, 4230. (b) Shi, Q.; Fan, H.; Liu, Y. J. Phys. Chem. C 2010, 114, 16843.

[9] Zhang, X.; Köhler, M.; Matzger, A. J. Macromolecules 2004, 37, 6306.

[10] Qin, R.-P.; Bo, Z.-S. Macromol. Rapid Commun. 2012, 33, 87. 